\title{
Prospects for the Expanded Use of Lignocellulosic and Grass Biomass Fuels in Ireland's Energy Mix - What Role for Policy?
}

\author{
Martin W. Leahy and Dan O’Sullivan
}

\begin{abstract}
Ireland's low fuel diversity and reliance on imported fossil fuels, allied with the threat of impending fines based on ambitious EU and global targets, have renewed interest in sustainable, indigenously-derived biomass energy sources.

Establishment of relevant lignocellulosic \& grass biomass (LGB) fuels, together with appropriate conversion technologies, has been combined with policy analysis, external benchmarking of high achieving bioenergy markets and utilisation of established investment \& policy appraisal techniques within targeted case studies, to identify the necessary criteria for policy design to successfully address short (2020), medium (2030) and long (2050) term targets.

Analysis indicates that the immaturity of the Irish bioenergy market and rapidly approaching policy deadlines dictate the need for aggressive fiscal policy in the short term (10-15 years). However, benchmarked countries (such as Sweden) have shown that in the medium/long term, economic sustainability of LGB-derived energy requires a sophisticated regulatory and fiscal policy mix.
\end{abstract}

Index Terms-Biomass economics, renewable energy policy, renewable heat incentive, renewable heat policy.

\section{INTRODUCTION}

The question of how to successfully design \& implement domestic policy measures for the deployment of renewable energy (RE) projects, infrastructure and crop production has been a major point of debate politically and academically [1]-[4]. Presently, at least 96 countries have engaged in RE policy targets or renewable support policy measures to promote RE heat and power generation with approximately 67 different energy policies arising both from the European Union (EU) directive and from the country's national initiatives [5]. There are many distinct energy policy drivers which include the following relevant to Ireland:

- Security of energy supply - self-sufficiency, reliability

- Environmental responsibility - reduction of harmful emissions, minimizing the negative effects of energy sourcing and use.

- No EU fines. The SEAI estimate that for each percentage point Ireland falls short of the $16 \%$ legally binding EU GFC target fines may be incurred in the range of $€ 100-€ 150$ million [6].

- Reduction in imported fuel bill. Potentially $€ 1 / 2$ billion per annum [7].

- Improvement of farm incomes [8].

Manuscript received May 19, 2015; revised December 29, 2015.

The authors are with the Institute of Technology Carlow, Ireland (e-mail: martin.leahy@itcarlow.ie).
- Improving and strengthening the competitiveness of Irish industry by minimizing carbon taxes, reducing fuel costs and protecting against fossil-fuel price volatility.

- Increase industry competitiveness by reducing energy costs for end users particularly in areas off the natural gas grid.

- Creating assured local markets which insulate end users from future fossil fuel price rises and provide improved returns for growers.

- Increasing the biodiversity of farm land.

However, RE drivers can often require a different set of programs and technologies, which can result in RE policy decaying into a chaotic process of seeking only to satisfy stakeholders, whilst losing sight of the larger goals [9]. Governments use many different types of policy measures in order to stimulate sustainable sector growth. Table I outlines typical RE policy measures associated with energy production in Europe.

TABLE I: POLICY EXAMPLES ASSOCIATED WITH EUROPEAN ENERGY

\begin{tabular}{|c|c|c|c|}
\hline \multicolumn{4}{|c|}{ PRODUCTION } \\
\hline \multirow{4}{*}{$\begin{array}{c}\text { Renewable } \\
\text { Energy Policy }\end{array}$} & \multirow[t]{2}{*}{ Regulatory } & Direct & $\begin{array}{l}\text { - Planning } \\
\text { Regulations } \\
\text { - Guidelines } \\
\text { - Standards } \\
\text { (Renewable Portfolio } \\
\text { Standards) }\end{array}$ \\
\hline & & Indirect & $\begin{array}{l}\text { - Waste management } \\
\text { policy \& regulation } \\
\text { - Fossil Fuel Bans }\end{array}$ \\
\hline & \multirow[b]{2}{*}{ Fiscal } & Direct & $\begin{array}{l}\text { - Direct Payments } \\
\text { - Grants } \\
\text { - Subsidies } \\
\text { - Feed in Tariffs } \\
\text { (FITs) } \\
\text { - Tax Credits } \\
\text { - Payments for } \\
\text { Environmental Services }\end{array}$ \\
\hline & & Indirect & $\begin{array}{l}\bullet \quad \text { VAT reduction on } \\
\text { energy efficient goods \& } \\
\text { Services } \\
\bullet \quad \text { Fossil Fuel } \\
\text { Taxation } \\
\bullet \quad \text { Environmental } \\
\text { Taxation } \\
\text { (Pollution,Carbon Taxes) } \\
\bullet \quad \text { Landfill Levy }\end{array}$ \\
\hline
\end{tabular}

\section{RESEARCH METHODOLOGY}

The major objective of this policy research is to assess policy incentives and regulations required over time to facilitate sustainable development of the relevant LGB fuel production in Ireland, in order to meet EU RE policy targets. The key pillars of investigation are shown in Fig. 1. 


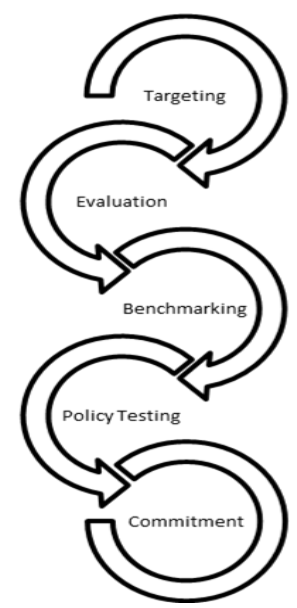

Fig. 1. Pillars of investigation.

Targeting the relevant conversion technologies and LGB fuels through case studies and an extensive literature review can essentially eliminate the requirement for numerous sets of policy measures. The literature review has identified anaerobic digestion \& thermochemical conversion technologies as having the greatest potential impact utilizing LGB fuels on reaching Ireland's 2020 RES-H targets (See Table II).

Evaluation of existing \& superseded policy associated with LGB fuel and energy production determine the success and failure factors associated with domestic RE policy.

Policy testing is carried out with a number of economic "real-world" agri-based case studies. Access and control of fuel supply chains for LGB fuels and alternative feedstocks within the agri-sector provide a unique opportunity for early adoption of RE projects within an immature market. Each case study employs a fossil fuel/ agri-residue based experimental control for economic comparison. The impact on investment of fiscal policies is tested through a sensitivity analysis and investment appraisal methods. The effect of Regulatory policy is tested through an extensive interview process. The case study offers a "real world" snap shot of the current economic climate regarding RE project investment and fuel production.

Key success factors for any support schemes for bioenergy investments include not only the economicincentive, but also the long term security of conditions. Commitment to policyfrom government, both in duration and resourcescreate market confidence and provide a foundation for sustainable economic growth. The level of commitment must correlate to the life cycle of the energy plant/LGB fuel. Long term governmental commitment to RE policy can also aid in capital acquisition/loan procurement for project development. The tax relief support for biofuels is one example of where domestic policy commitment has failed. The policy is thought to be one of the main facilitators for the development of biofuels in Ireland and ceased in 2010. The replacement measure, the biofuels obligation scheme (BOS) created a market crisis and ultimately hindered any further development of biofuels in Ireland [10].

\begin{tabular}{|c|c|c|c|}
\hline Category & Definition & Selected Crops & Conversion Technologies \\
\hline $\begin{array}{l}\text { Lignocellulosic } \\
\text { Fuels }\end{array}$ & $\begin{array}{l}\text { Perennial crops are crops that can be harvested on average once a year } \\
\text { over several years without the need for ploughing up and new planting. } \\
\text { SRC refers to plants and trees that are harvested by cutting the growing } \\
\text { stem to its base, allowing the growth of new stems }\end{array}$ & $\begin{array}{l}\text { Miscanthus, } \\
\text { Willow SRC. }\end{array}$ & $\begin{array}{l}\text { Thermochemical Combustion } \\
\text { Combined Heat \& Power } \\
\text { (CHP), } \\
\text { Thermochemical Combustion }\end{array}$ \\
\hline $\begin{array}{l}\text { Grass Biomass } \\
\text { Fuels }\end{array}$ & $\begin{array}{l}\text { Perennial energy grass crops of interest are mainly indigenous } \\
\text { herbaceous grasses. }\end{array}$ & $\begin{array}{c}\text { Perennial Rye } \\
\text { Grass } \\
\text { (Loliumperenne) }\end{array}$ & Anaerobic Co-Digestion \\
\hline
\end{tabular}

\section{ELECTRICITY SECTOR-CURRENT STATUS}

Ireland's RE industry is characterized by wind power and electricity, although electricity is expected to account for only $23 \%$ of GFC of energy in 2020 [11]. In 2005 the European Commission noted that the effectiveness of support mechanisms for biomass in member states was less than that for wind and that biomass was lagging behind expectations at EU level [12].

Wind power investment (280-480 €m/year) in Ireland is driven by a high quality wind resource, mature technology resources, supportive policy measures, such as the Renewable Energy Feed-In Tariff (REFIT) scheme which attract investors through lower payback periods, periodical payments (REFIT paid to the licensed supplier) and ease of bank loan access [13]. The cost of electricity generated from biomass CHP is also more expensive than that of wind energy per unit (approximately 7 cent per kWh) [14].

Growth in the RES-E share is sufficient to achieve the 2020 electricity target if maintained. Wind power project development has progressed at a steady pace since 1992, with installed capacity reaching $1,732 \mathrm{MW}$ in 2012. Fossil fuel \& $\mathrm{CO}_{2}$ emission savings are estimated at $€ 177$ million \& $€ 11$ million respectively [15]. Bioenergy sourced electricity generation accounts for just $88 \mathrm{MW}$ of the 12,007 MW installed capacity [15] see Fig. 2).

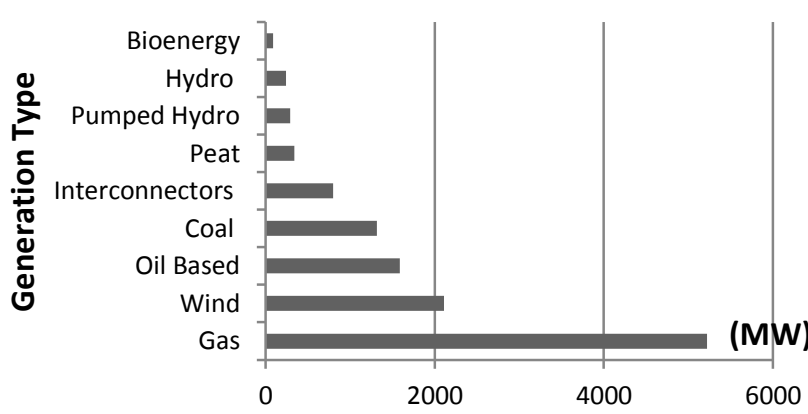

Fig. 2. All-island electricity system capacities by generation type (MW), 2012 (adapted from [15]).

\section{Heat SECTOR - CuRrent Status}

The Irish heat market is comprised of 4 specific sectors (see Fig. 3) with the residential market accounting for the majority share. Bioenergy for heat is predominantly used in large-scale applications to produce process heat where 
biomass boilers are competitive with oil. A significant portion of space heat requirements, particularly in larger buildings, is met by biomass [13].

\section{- Residential Industrial \\ - Services Agriculture}

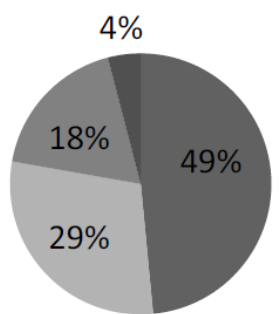

Fig. 3. Ireland's heat energy market share.

The heat market is the most suitable application for lignocellulosic fuels. It is widely accepted that Ireland will not meet its 2020 12\% RES-H target at the current rate of progression [16] even with the proposed introduction of a renewable heat incentive in 2016 [17] (see Fig. 4). Whilst avoiding penalties is highly unlikely, introduction of appropriate policy measures could reduce fiscal penalties incurred. Ireland's RES-H shortfall is $6 \%$ (2\% of overall RES shortfall) [18]. Industrial heat users offer larger incremental returns, with an estimated 200 industrial heat users required compared to 2,000 service sector buildings,300,000 dwellings or 438MW overall in order to reach Ireland's 2020 RES-H targets [19].

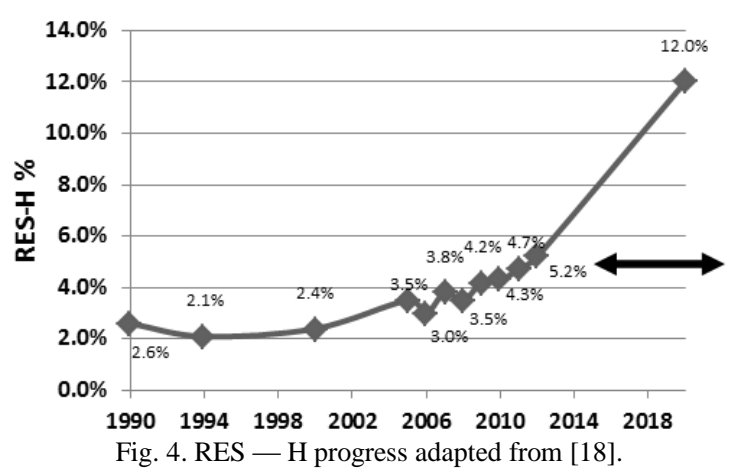

\section{IRELAND RE POLICY BACKGROUND}

Ireland has committed to a number of ambitious RE targets both domestically and internationally. Fig. 4 shows the sequence of (LGB relevant) policy measures that have been implemented in Ireland since 1991 (see Fig. 5).

The European Union (EU) renewable energy (RE) Directive (2009/28/EC) requires each EU member state to produce a national renewable action plan (NREAP) in order to meet $20 \%$ gross final energy consumption (GFC) by the year 2020. The 2007 Irish government "White Paper" entitled Delivering a Sustainable Energy future for Ireland took the landmark approach of setting action plans towards meeting the EU's 2020 targets for RES-E (33\% inc. since to 40\%), RES-T (10\%) and RES-H (12\%). An additional target was also set of $30 \%$ co-firing by 2015 with biomass at the three state owned peat power generation plants.

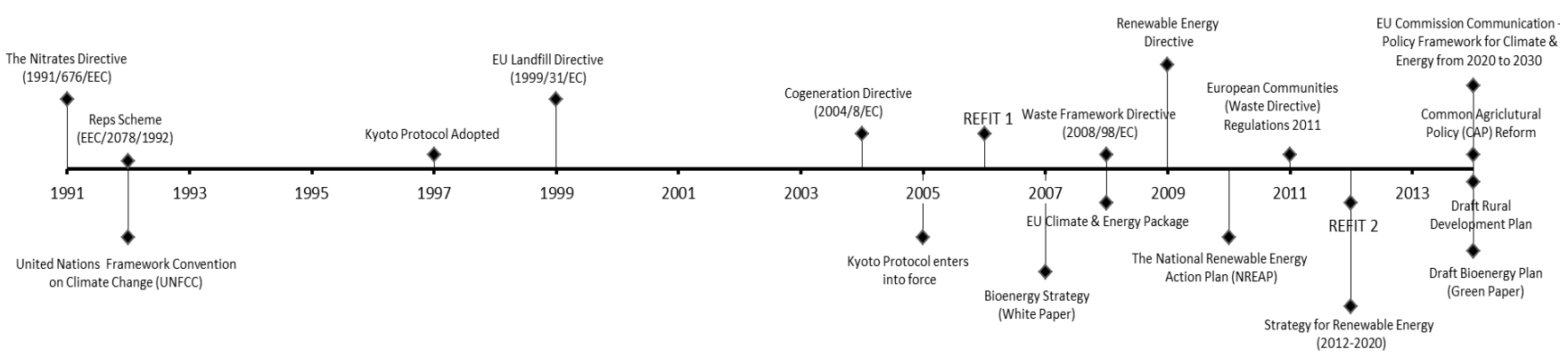

Fig. 5. Ireland's (LGB relevant) policy timeline.

\section{IRELAND's ENERGY CROP PRODUCER POLICY MEASURES}

The two main types of agricultural land use in Ireland are grassland and arable, with both suitable for LGB energy crop production. In order to meet the RES-H shortfall $12.3 \%$ of arable land or $1.23 \%$ of grassland is required.

Due to Ireland being only $80 \%$ self-sufficient in cereals [20] and increased pressure on grassland due to the elimination of milk quotas, a LGB production mix is initially proposed.

The financial incentives from the Irish government to support renewable energy development are inadequate. Teagasc estimates that during 2013 almost 500 hectares of miscanthus have been removed alone [21].

A number of amendments are proposed to existing policy measures in order to ensure an attractive investment environment for the production of LGB fuels. LGB relevant producer policies include The Bioenergy Scheme, Common Agricultural Policy (CAP) Reform, Draft Bioenergy Plan \& Common Agricultural Policy Reform.

\section{CAP REFORM 2014}

The CAP has been through many successive reforms with the main objectives being to increase market orientation for agriculture, while providing income support and safety net mechanisms for producers, improved the integration of environmental requirements and reinforced support for rural development across the EU [22].

The most recent (CAP) reform has been revised for the period 2014-2020. The revised CAP has increased focus on bioenergy production \& climate action; however, a number of bioenergy related measures could have been further exploited in order to enhance LGB production. The new CAP retains modified versions of the two pillar payment scheme; however a new mandatory policy under pillar 1, the green direct payment, has been introduced (see Table III).

Ireland is allocated $€ 313$ million per year under pillar 2 of the CAP for a new rural development programme (RDP), which now can also supports biomass enterprise. Capital grants are required for targeted investment in processing, 
storage and marketing of LGB fuels in order to support RE infrastructure and correct supply chain issues.

\section{A. Green Direct Payment}

Greening forms a major portion of CAP 2015 accounting for $30 \%$ of the national direct payments bursary. Greening includes agri-environmental climate measures, organic farming, areas of natural constraint and additional measures which are beneficial for the environment. Farmers who participate in the Basic Payment Scheme must implement and comply with the three standard greening measures as follows;

- Greening practices must be observed on all of farmer's eligible hectares, i.e. not just on the area covered by entitlements.

- Crop diversification requires producers to grow a minimum of 3 crops on all arable areas over 30 ha.

- Requirement to maintain permanent pasture at 2014 area at individual farm level (5\% flexibility).

\section{B. Ecological Focus Area}

Various authors [23]-[26] have outlined the positive impact miscanthus \& willow SRC have on biodiversity. Despite these benefits crops such as miscanthus \& willow SRC are not compliant with EFA regulation. The European Commission shall be permitted to adopt delegated acts to further define the types of EFA [27] and has the authority to provide attractive measures to grow dedicated LGB fuels on EFA'S.

\begin{tabular}{|c|c|c|}
\hline $\begin{array}{c}\text { CAP Reform Policy Critique \& } \\
\text { Advised Amendments }\end{array}$ & $\begin{array}{l}\text { Regulatory } \\
\text { Measure }\end{array}$ & $\begin{array}{l}\text { Fiscal } \\
\text { Measure }\end{array}$ \\
\hline $\begin{array}{l}\text { Payments should reflect the } \\
\text { multi-functional benefits of perennial } \\
\text { energy crops such as Willow SRC. } \\
\text { - No less than } 12 \text { priority bird species } \\
\text { covered by Biodiversity Action Plans } \\
\text { are frequently found in and around } \\
\text { energy crop plantations. } \\
\text { multi-functional around energy crops } \\
\text { encourage butterfly and other } \\
\text { invertebrates. } \\
\text { Woody energy crops can } \\
\text { significantly increase biodiversity on } \\
\text { farms. }\end{array}$ & $\checkmark$ & 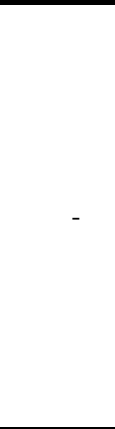 \\
\hline $\begin{array}{l}\text { Renewable energy and raw material } \\
\text { production is given much attention in the } \\
\text { CAP Reform, although the CAP does not } \\
\text { set production targets, no direct supports or } \\
\text { mechanisms put in place to stimulate LGB } \\
\text { fuel production or to encourage switching } \\
\text { from grassland to energy crops. }\end{array}$ & - & $\checkmark$ \\
\hline
\end{tabular}

\section{THE BIOENERGY SCHEME}

The Irish Department of Agriculture's Bioenergy Scheme provides establishment grants to farmers to grow willow SRC and miscanthus for the production of biomass suitable for use as a renewable source of energy. Grant aid is payable on 50\% of the approved costs associated with establishing the crop, subject to a maximum payment rate of $€ 1,300$ per hectare, with the balance to be invested by the applicant. Eligible costs include those associated with ground preparation, fencing, vegetation control, the purchase of planting stock and planting. Areas planted with willow and miscanthus also qualify for the Single Farm Payment and payments under the
REPS and Disadvantaged Areas Scheme, subject to some restrictions on the areas planted (see Table IV).

TABLE IV: BIOENERGY SCHEME CRITIQUE AND ADVISED AMENDMENTS Bioenergy Scheme Critique \& Advised Regulator Fiscal Amendments y Measure Measure

Elimination of the maximum plantation area permissible (30ha) regulation in order to facilitate larger/multiple facilities if required. Pay a flat rate of $€ 1,300$ per hectare (the maximum amount) in order to reduce instances of bureaucracy and to further incentivize and simplify willow/miscanthus production and application process.

Cashflow is regarded as a major barrier within the energy crop production sector with anecdotal evidence suggesting farmers having to wait 3 years before collecting harvest revenue. Support mechanisms (similar to the forestry sector) where famers receive support payments in the initial establishment years could potentially increase the number of candidates applying to the scheme.

Bioenergy scheme applicants must provide a multiyear legally binding commitment from energy crop end users in order to be applicable for the scheme. This measure would drastically reduce the instances of failed schemes and assure producers of incomes.

In the UK the energy crops scheme provides establishment grants as well as a 50\% concession for setting up coppice producer groups. A similar measure in Ireland could incentivize market development.

\section{IRELAND's ENERGY CROP CONVERSION POLICY MEASURES}

Recent publication of the draft bioenergy plan "Green Paper" outlines a tentative framework for RE policy with a number of key measures relevant to LGB production outlined in the bioenergy plan (see Table V).

TABLE V: DRAFT BIOENERGy Plan AND ADVISED CRITIQUE

\begin{tabular}{|c|c|c|}
\hline $\begin{array}{c}\text { Draft Bioenergy Plan Critique \& } \\
\text { Advised Amendments }\end{array}$ & $\begin{array}{l}\text { Regulatory } \\
\text { Measure }\end{array}$ & $\begin{array}{r}\text { Fiscal } \\
\text { Measure }\end{array}$ \\
\hline $\begin{array}{l}\text { Investment in the renewable heat projects has } \\
\text { stagnated due to a lack of clarity surrounding RHI } \\
\text { qualifying criteria and tariff tiering/banding etc. } \\
\text { Potential RE Investors are uncertain if projects } \\
\text { commissioned pre } 2016 \text { will be eligible for the } \\
\text { RHI. Clarity is required in order to facilitate } \\
\text { project development, planning, fuel supplier } \\
\text { negotiations, construction etc. and prevent further } \\
\text { stagnation of the bioenergy market. }\end{array}$ & $\checkmark$ & - \\
\hline $\begin{array}{l}\text { No further details regarding eligibility, energy } \\
\text { pricing structure are contained within the report } \\
\text { however due to Northern Ireland having a RHI } \\
\text { since } 2012 \text { there is a need for market alignment } \\
\text { regarding pricing structure in order to avoid } \\
\text { market distortion in what effectively is a single } \\
\text { all-Ireland energy market. An aligned RHI and } \\
\text { FIT market will provide equal growth } \\
\text { opportunities between both markets. This } \\
\text { initiative will prevent incongruities such as } \\
\text { feedstock produced in the Republic of Ireland } \\
\text { being transported to economically sustainable } \\
\text { conversion facilities in Northern Ireland and vice } \\
\text { versa. }\end{array}$ & - & $\checkmark$ \\
\hline $\begin{array}{l}\text { Long term fixed tariffs are required ( } \geq 5 \text { years) in } \\
\text { order to provide market stability and investor } \\
\text { confidence. Long term fixed tariffs will increase } \\
\text { the accuracy of life cycle cost analysis (LCCA) } \\
\text { and provide a strong case for bank finance where } \\
\text { applicable. }\end{array}$ & - & $\checkmark$ \\
\hline $\begin{array}{l}\text { The scheme needs to be applicable to both } \\
\text { non-domestic and domestic end users in order to } \\
\text { further increase deployment of RE projects as } \\
\text { well as to provide equal RE investment } \\
\text { opportunity to taxpayers. }\end{array}$ & $\checkmark$ & - \\
\hline
\end{tabular}




\section{Benchmarking Key Market TREndS AND SUPPORT MECHANISMS}

Benchmarking of foreign \& domestic policy measures within mature markets such as Germany, Sweden etc. aid in determining the success criteria required to incentivize market development in an immature market like Ireland. A policy measure is likely to be more effective if it builds on or leverages existing policies and markets.

High achieving bioenergy markets benchmarked in the paper include Austria, Sweden \& the United Kingdom. This section seeks to identify the relevant measures that have assisted market development of LGB fuels. Table VI summarizes and classifies the major policy measures associated within the selected countries.

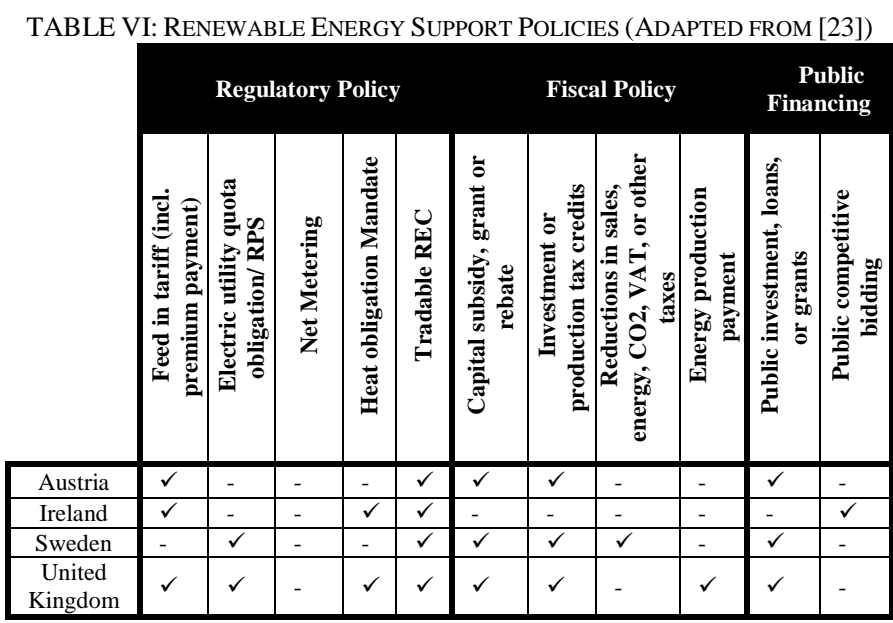

\section{THE UnITED KINGDOM}

Ireland is set to introduce a renewable heat incentive in 2016 anticipated to be similar to the pioneering UK RHI scheme. The UK scheme was announced in June 2009 and launched in 2011. Less than $1 \%$ of UK heat was renewable prior to 2011 with $14 \%$ required to meet legally binding 2020 targets [24].

\section{A. Non-Domestic Renewable Heat Incentive (RHI)}

The scheme is funded through taxation and payments are made quarterly over a 20 year period based on the metered heat generated $(\mathrm{p} / \mathrm{kWh})$. Over 1,300 innovative renewable heat technologies have already been installed $(98.7 \%$ accredited to solid biomass) under the UK RHI scheme with over $£ 90$ million paid to generators to date [24]. The RES-H\&C target share for 2012 has been exceeded.

There are a number of key eligibility requirements including:

- Equipment must be new at time of installation

- Grants not received for purchase/installation of equipment

- Medium of heat transfer must be liquid or steam

- The heat must be utilized for space heating, hot water, carrying out a process etc.

- Eligible candidates must provide periodic data and compliance with site inspections

\section{B. Lessons to Be Learned From UK RHI}

- The tariff structure has led to a disproportionate granting of funding to sub-200 kW boilers (see Fig. 8) and has had unintended consequences including encouraging boilers to be both oversized and undersized for their requirement leading to technology and public finance inefficiencies (see Fig. 5).

- Biomass combustion conversion technologies have been disproportionately popular (see Fig. 6).

- Six sets of regulations in the last $31 / 2$ years have reduced market confidence.

The RHI uses a "degression" budgeting system in order to manage the scheme finances. Applicants who are registered onto the scheme once the notice period ends will receive the new (reduced Tariffs). Those who have already been registered onto the scheme will continue to receive the previous tariffs. Degression has produced significant pressure to install to deadlines in order to avail of the superior tariff structure. Installers who become preoccupied with new installations can be disinclined to spend time helping potential applicants through the application process [25].

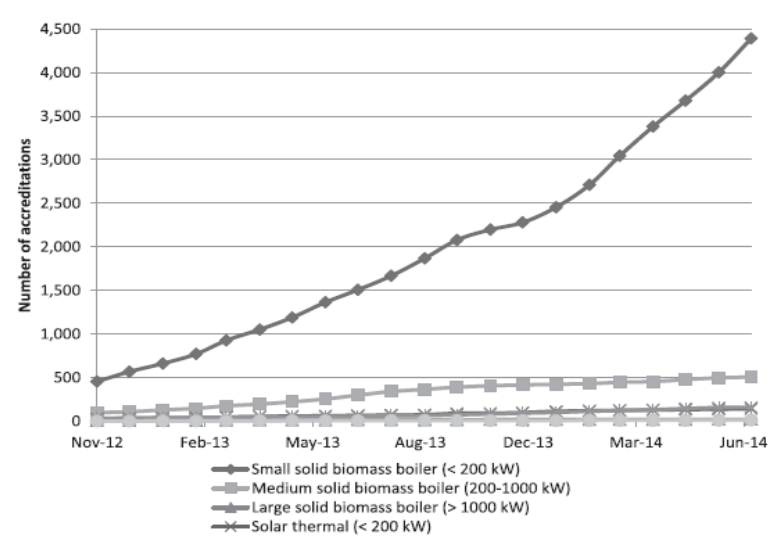

Fig. 6. Non-domestic RHI applications and accreditations Source: DECC (2014) RHI and RHPP deployment data: July 2014

- Metering may be incentive for overproduction.

- Constant changes to RHI support scheme have caused confusion and slow uptake. Further changes considered in the next 2 years should be relatively minor - even welcome changes can cause deployment to stall as industry waits to see if something better will come along.

- The scheme currently has funding agreed only to end of March 2016. This timeframe is already too short for projects that take longer to deploy and is likely to become more acute as this deadline gets closer. Industry has a lack of confidence in Government's commitment to RHI long-term funding and uptake has been slower as a result.

\section{Subsidies, Grants and Support Schemes}

The UK has an established history of applying grants to support the development of small scale renewable energy and pre-RHI this was the only significant instrument to support RES-H deployment [26]. However, similar to the Irish Context, this application has so far been budget limited.

\section{SWEDEN (BIOGAS POLICY)}

\section{A. Introduction}

The largest resource of bioenergy in Sweden is the forest but the energy produced from agricultural land and from 
sewage treatment is substantial [27]. Sweden is considered as a benchmark for a well-developed and differentiated bioenergy market, as well as a competitive national industry [28].

Sweden has geared its biogas policy towards the treatment of waste, through efficient use of anaerobic digestion capacity at waste water treatment plants and through a few but highly optimized agricultural plants focusing on digesting manure.

The strong growth of the Swedish bioenergy market can be credited to a range of regulatory and fiscal policy measures. The majority of key policy measures are indirect, such as taxation on fossil fuels, but some are direct, including grant aid for the construction of biogas plants in agriculture.

\section{B. Taxation Policy}

The taxes employed in Sweden have been consistently high and frequently revised, but consistently supportive of biofuels \& bioenergy at the expense of fossil fuels. Sweden has used taxation very effectively to increase levels of bioenergy and renewable generation. In order to have a competitive economic climate industry pays a lower carbon $\operatorname{tax}\left(20 \mathrm{~h} /\right.$ tonne $\mathrm{CO}_{2}$ 2002) than users in other sectors $(70$ $\mathrm{h} /$ tonne $\mathrm{CO}_{2}$ 2002) [29]. Biomass became less expensive than coal in 1991 as a result of carbon and energy taxes and as a result has become the least costly fuel for heat generation in Sweden [29].

\section{Subsidies, Grants and Support Schemes}

Sweden has employed various investment and production support schemes in addition to its taxation policy. For the specific action to invest in biogas facilities there was $€ 200$ million earmarked for the period 2009-2012 to support biogas project development. Another $€ 100$ million will be used during the years 2010 -2014. Biogas support has been given to investment to produce, store and process the biogas, mainly from manure raw material.

\section{Regulation}

Regulatory actions such as the ban on landfilling organics (all organics 2005) \& combustible waste (2002) have incentivized public and private operations to consider alternative waste disposal techniques like anaerobic digestion

- National targets for source separation of organics (by $2018>50 \%$ source separated at homes, restaurants, industrial kitchens and grocery stores and $>40 \%$ biologically treated so as to recycle the nutrients and recover energy) have highlighted the government's commitment to efficient use of waste.

- 5 years of road tax exemption for biogas vehicles

- Explicit preference given to biogas vehicles when tendering for municipal and regional fleets and services (buses, taxi, recycling collection, home care, etc.)

- Free parking and road toll exemptions for biogas vehicles

\section{AUSTRIA}

\section{A. Introduction}

Austria also has a long tradition of support to the development of the biomass wood energy sector [30], [31].
For heat production, a large number of regional and federal programmes to support development of biomass installations exist, and cover between 20 and $40 \%$ of total investment costs. The state has provided long-term support to all aspects of biomass boiler deployment, including legal obligations for use in large buildings, minimum standards for boiler emissions, financial incentives and public education programmes for potential end-users. New professional qualifications were introduced for installers and advisors. The supply chain invested $€ 37 \mathrm{~m}$ in $110 \mathrm{R} \& \mathrm{D}$ projects, $€ 7.4 \mathrm{~m}$ of which was provided through a system of grants. Such initiatives have made Upper Austria one of the leading biomass regions in Europe and worldwide.

In comparison to Ireland, however, Austria has a natural advantage in the supply of solid bio-fuel, as $47 \%$ of its total land area is covered in forests, compared to only $11 \%$ in Ireland. While the physically available biomass resource may expand in Ireland in the future, this will depend on the market price for bio-energy. At present, wide availability of biomass for import into Ireland is likely to lower the price for domestic bio-energy, thus discouraging local production. More detail is available in Bioenergy Supply Curves for Ireland (SEAI, 2013).

\section{B. Subsidies and Support Schemes}

Austria has investment subsidies for approx. $25 \%$ of total investment costs including:

- Engineering/quality management.

- Boiler house.

- Components.

- Piping and electricity.

- District heating network.

C. Regulation

- Set of technical standards/norms and qualification measures in place.

- Standards and certificates for installations and installers.

- First country to introduce quality standard for wood pellets.

- Support scheme linked to quality criteria.

- Scheme also includes comprehensive trainings for planners, installers and chimney-sweepers.

\section{Policy Testing - CASE StUdies}

\section{A. Introduction}

The largest share (37\%) of the UK RHI accredited installed industrial capacity is associated with crop and animal production and related services activities [32]. With Ireland expected to be implement a similar scheme in 2016, agri based-case studies are utilized to gauge the perceived success or failure of bioenergy projects. The Irish agriculture sector is the largest emitter of greenhouse gas $(32 \%)$ followed by transport (19\%) \& industry \& commercial (15\%) [15]. Agriculture offers potential investors the opportunity to insulate themselves from variations in the price of both fossil fuels and even biomass fuels. Agricultural enterprises can also have complete project process control, including fuel production, storage, supply \& biomass conversion.

Fiscal policy measures are potentially the most direct 
method for rapid deployment of the RE projects, as Ireland nears its 2020 obligations and requires reduction in impending fines associated with non-compliance. The case studies focus on a number of fiscal policy measures including:

- Renewable Heat Incentive

- Capital Grant Support.

- Feedstock Subsidies

For the purpose of this paper, the case study on poultry is selected. The relevant business is actively researching alternative heating methods, and market conditions permitting, would invest in cost saving measures, such as a renewable heating system. The investor is a prime example of market stagnation compounded by a perceived lack of clarity from the latest draft bioenergy plan.

\section{B. Investment Appraisal Definitions and Policy Assessment}

Without economic viability, market implementation of LGB fuels is unlikely to be successful. In order to assess the economic effect of fiscal policies investment appraisal methods, allied with a sensitivity analysis, are utilized.

The Net Present Value (NPV) method is utilized in order to compare the relative cost of each RE project scenario and calculates the total project cost $(€)$ after $n$ years. The method is frequently used [33]-[36] as it takes into account the real-time value of money. The NPV investment appraisal method converts all annual expenditure and revenue over the project lifespan into their present values, and then sums them to obtain the NPV. Projects with positive NPVs are considered to be attractive investment opportunities.

The Internal rate of return (IRR) is defined as the discount rate at which the after-tax NPV is zero. The calculated IRR is examined to determine if it exceeds a minimally acceptable return, often called the hurdle rate. The advantage of IRR is that, unlike NPV, its percentage results allow projects of vastly different sizes to be easily compared.

A payback calculation compares revenues with costs and determines the length of time required to recover the initial investment. A Simple Payback Period is often calculated without regard to the time value of money. This figure of merit is frequently used to analyze retrofit opportunities offering incremental benefits and end-user applications.

The uses of a sensitivity analysis are grouped into four main categories: decision making or development of recommendations for decision makers, communication, increased understanding or quantification of the system, and model development (Pannell, 1997). A sensitivity analysis is employed in this paper to measure the effect typical fiscal policy measures have on lignocellulosic biomass project investment.

\section{Poultry Business Case Study Rationale}

Key reasons for investment in RE systems include:

- Broiler chickens are raised in large sheds/houses that often accommodate tens of thousands of birds at a time. Temperate climates such as Ireland require heating the majority of the year with space heating accounting for over $80 \%$ of the total energy consumption [37].

- The Nitrates Directive has restricted the amount of grassland available for application of chicken manure. This directive has led to a surge in alternative waste management techniques for chicken litter disposal.
- Recent regulatory changes (Commission Regulation (EU) No 592/2014) have now given poultry farmers the opportunity of combusting chicken litter $(<1 \mathrm{MW})$ on site. The technology and systems exist to allow this to happen already and a recent amendment recently to legislation no longer classifies poultry litter as waste material when combusted.

- Poultry litter is currently utilized as mushroom compost (disposal fee $€ 12.60$ per tonne).

- The industry is seriously affected by cheap imports from third countries. Ireland, with its high cost base for raw feed ingredients, is unable to compete economically [37]. Ireland is the highest consumer per head of poultry meat in the EU. A poultry enterprise must aspire to reach current state of the art.

- Converting to Biomass provides a cost-effective, low-carbon alternative to fossil fuel heating, with reduced carbon dioxide helping to get the chicks off to a better start. Heat that is evenly distributed will stop the birds huddling together, reducing stunting. It also helps to keep the litter drier, reducing ammonia and further boosting growth, by around $4 \%$.

- Recent construction of a new broiler house will see annual cost of LPG fuel reach an estimated $€ 80,000$.

\section{Current Heating Method \& RE Conversion Options}

The poultry business currently employs an LPG (Liquid Petroleum Gas) heating system in each of the existing 3 broiler houses. The system has the advantage of relatively low capital costs, fuel that is easily sourced and can readily turn on /off intermittently to meet the temperature demands of the building.

Extensive research and investor input has led to the development of two potential scenarios where RE systems could potentially be deployed (see Table VII).

\begin{tabular}{|c|c|}
\hline \multicolumn{2}{|c|}{ Renewable Energy Conversion Scenarios } \\
\hline RE Scenario 1 & $\begin{array}{l}\text { Willow Chip Combustion: 500kWthermal, } \\
\text { 80kWelectrical }\end{array}$ \\
\hline RE Scenario 2 & $\begin{array}{l}\text { Fluidised Bed (Chicken Litter) Combustion: } \\
\text { 500kWthermal, 50kWelectrical }\end{array}$ \\
\hline
\end{tabular}

\section{E. RE Key Assumptions}

TABLE VIII: RE DEPLOYMENT KEY ASSUMPTIONS

\begin{tabular}{|c|c|c|}
\hline \multicolumn{3}{|c|}{ RE Deployment Key Assumptions } \\
\hline Description & Scenario 1 & Scenario 2 \\
\hline Plant Lifespan & \multicolumn{2}{|c|}{15 Years [36] } \\
\hline Plant Efficiency $(n)$ & \multicolumn{2}{|c|}{$90 \%[38]$} \\
\hline Annual thermal Load & \multicolumn{2}{|c|}{$3,061,800 \mathrm{~kW}$} \\
\hline Discount Rate (\%) & \multicolumn{2}{|c|}{$10 \%$ [39], [40] } \\
\hline $\begin{array}{l}\text { Bank Finance Rate } \\
(\text { APR } \%)(100 \% \text { loan assumed })\end{array}$ & \multicolumn{2}{|c|}{$4.99 \%[41]$} \\
\hline Loan Period & \multicolumn{2}{|c|}{10 Years [42], [43] } \\
\hline Grid Connection & $€ 7000$ & $€ 7000$ \\
\hline Capital Expenditure (CapEx) & $€ 250,000$ & $€ 467,000$ \\
\hline Fuel Cost Delivered $(€ / \mathrm{t}$ dm) & $€ 108.42[44]$ & $-€ 12.60$ \\
\hline Tonnes/Year & 567 & 2177 \\
\hline $\begin{array}{l}\text { Poultry Litter Handling \& } \\
\text { Diesel start up }\end{array}$ & $€ 0$ & $€ 3000$ \\
\hline Labour/year & \multicolumn{2}{|c|}{$€ 0$} \\
\hline Maintenance/year & $\begin{array}{c}€ 20,000 \\
\text { (Contracted) }\end{array}$ & $\begin{array}{c}2 \% \\
\text { CapEx[45] }\end{array}$ \\
\hline $\begin{array}{l}\text { General Insurance, expenses \& } \\
\text { local tax }\end{array}$ & \multicolumn{2}{|c|}{$4 \%$ of CapEx[46] } \\
\hline LPG Fuel Displaced/Year & \multicolumn{2}{|c|}{$€ 80,000$} \\
\hline
\end{tabular}


In order to provide an accurate "real world" scenario quotations were obtained where possible. However, due to the complexity of biomass systems, a number of key assumptions were conservatively determined through an extensive literature review. Table VIII outlines the major assumptions employed in the study.

\section{RESUlts}

\section{A. Investment Potential without Policy Amendments}

Without policy incentives in place, scenario 1 is economically unfeasible. A negative NPV, long payback period (see Fig. 7) and a negative rate of return highlight the need for policy incentives (see Table IX) to aid in the development of capital intensive projects. Scenario 2 has a positive NPV but is still regarded as a high risk investment as it also has a relatively long PP and a very low IRR $(0.04 \%)$.

A change in the discount factor (see Fig. 8) to a $7 \%$ discount rate makes scenario 1 economically viable, however this does not reflect the perceived risk associated with RE investment in Ireland.

TABLE IX: INVESTMENT APPRAISAL WITH NO INCENTIVES, SUBSIDIES ETC.

\begin{tabular}{|c|c|c|c|}
\hline & NPV & $\mathbf{P P}$ & IRR \\
\hline Scenario 1 & $-39,059.08$ & 9.01 & $-7.03 \%$ \\
\hline Scenario 2 & $15,392.87$ & 7.86 & $0.04 \%$ \\
\hline
\end{tabular}

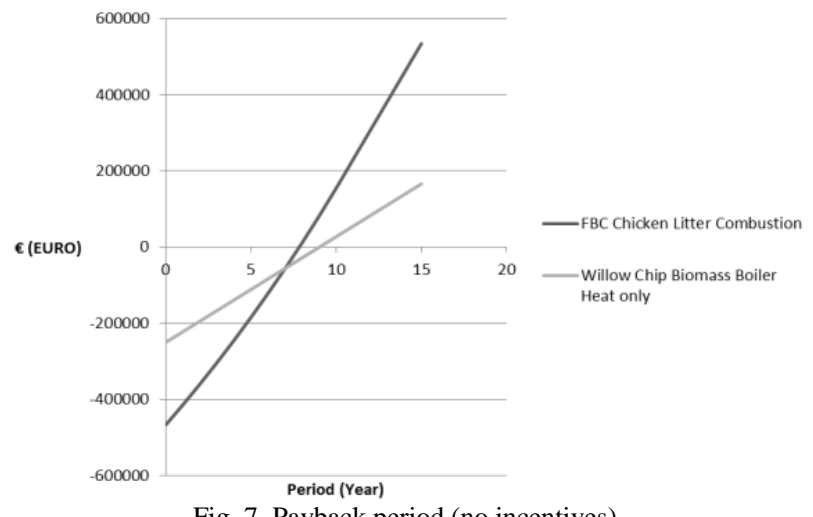

Fig. 7. Payback period (no incentives).

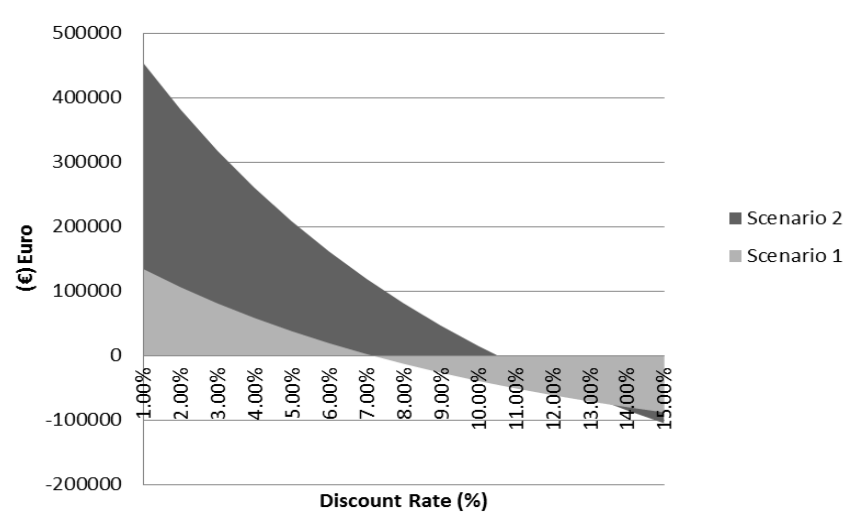

Fig. 8. Sensitivity of NPV with discount rate variance.

\section{B. Capital Grant Support}

The Irish CHP grant scheme provided for $40 \%$ funding for CHP feasibility studies and capital investment funding of $30 \%$ (one payment) on eligible CHP projects. However, due to the non-availability of budget resources for 2011 the Government's CHP Deployment Programme (administered by SEAI) is now closed indefinitely. Under the scheme a total installed capacity of just $3 \mathrm{MWe}$ of biomass CHP and 250 kWe AD were installed. (Howley, 2014).

Ireland is allocated $€ 313$ million per year under pillar 2 of the CAP for a new rural development programme (RDP) [47], which now also supports biomass enterprisefor intensive farmers selecting certain climate beneficial actions.

The application of an assumed capital grant of $30 \%$ increases the viability of both scenarios though lower PP's (see Fig. 10, 5.8,5.66 years), higher IRR,s (see Fig. 11, 8.78\%, $11.34 \%$ ) \& larger NPV's (see Fig. 9, €55, 906.88, €160, 820.93), however, the application of the grant leads to a larger gap between the NPV's of both projects $(€ 104,914.04$ difference) and has the unintended outcome of over-incentivizing one project in relation to another because of the larger capital cost outlay associated with chicken litter combustion.

The application of a capital grant subsidy is probably the simplist type of policy incentive for a consumer to understand and make investment decisions on. However, the application of a capital grant is not proposed due to a number of reasons:

- Policies must be economically andfinancially feasible. A capital grant scheme is expensive and will increase the financial burden on the Irish exchequer in the early years of the scheme.

- The application of a capital grant does not provide an ongoing incentive to provide renewable heat for the lifetime of the plant and as a result can lead to increased instances of project failure.

- Ireland like the UK (pre-RHI) already has mixed experience with capital grant application. In order for rapid deployment of RE projects and reduced instances of failed projects a more sophisticated policy measure is required.

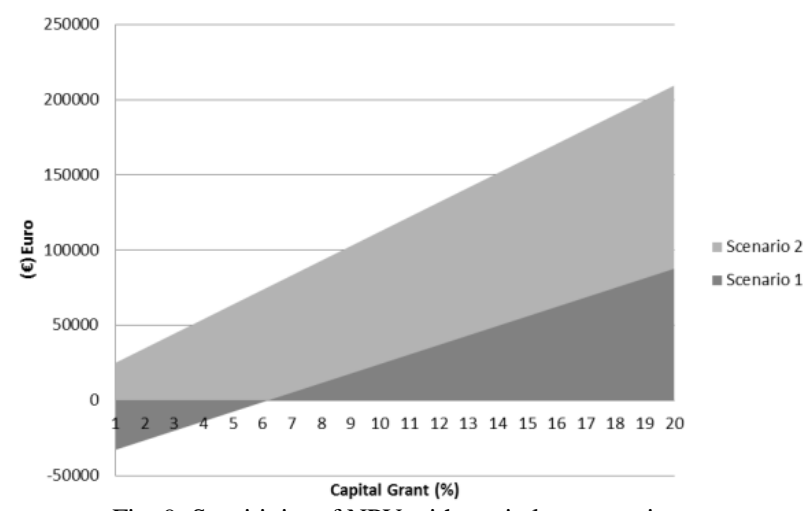

Fig. 9. Sensitivity of NPV with capital grant variance.

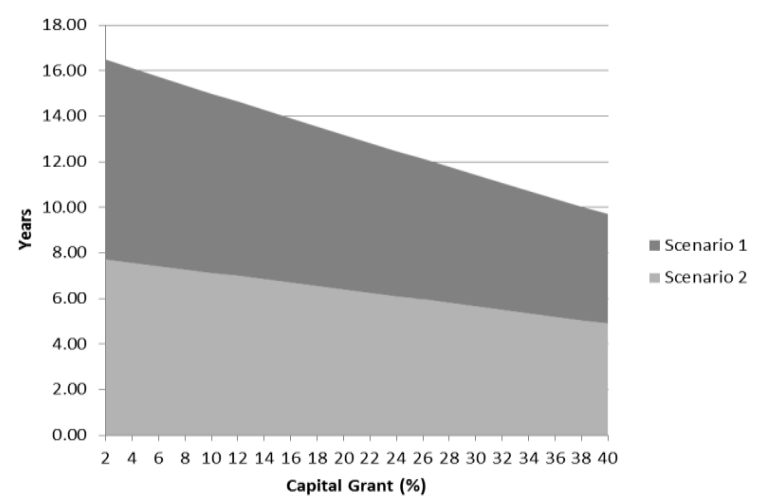

Fig. 10. Sensitivity of payback period with capital grant incentive. 


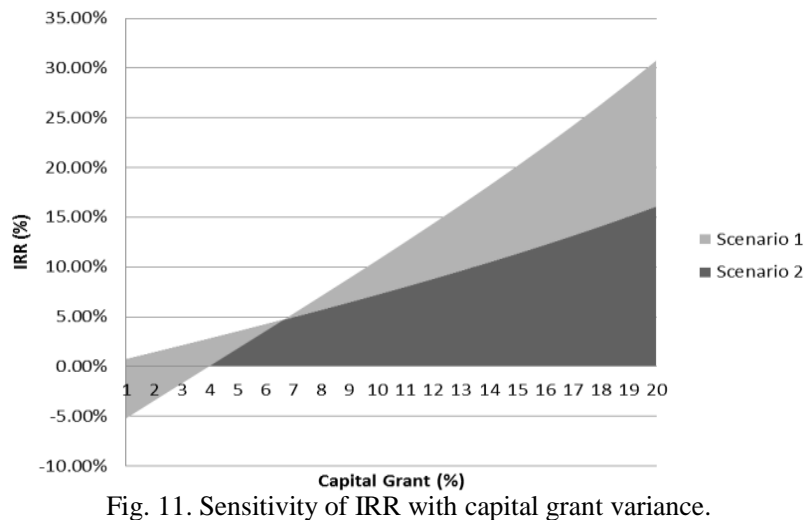

\section{Renewable Heat Incentive}

Coillte analysis shows that, with a subsidy of $1.5 \mathrm{c} / \mathrm{kWh}$, Ireland could expect to secure an uptake in installed thermal capacity of between 120-160 MW by 2020, which equates to a gross RHI cost to the Exchequer of between $€ 13.5$ million and $€ 18$ million (engineersjournal.ie, 2014).

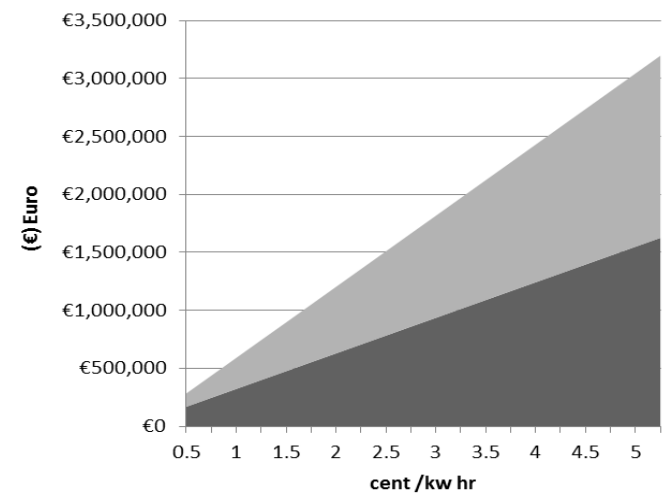

I Scenario 1 - Scenario 2

Fig. 12. Sensitivity of NPV with variance in RHI.

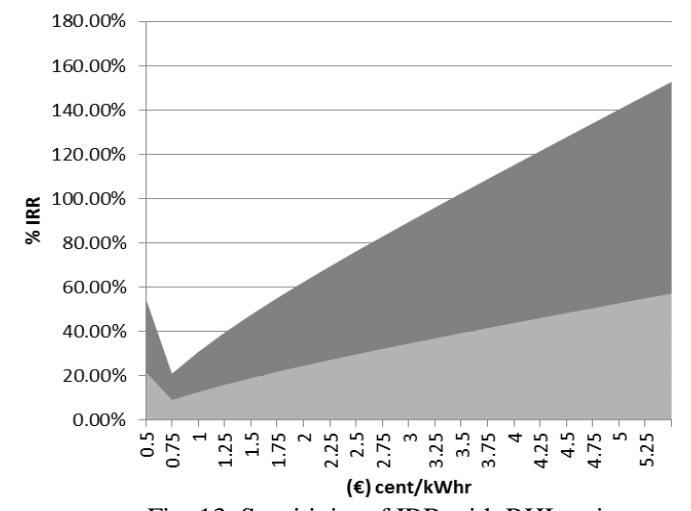

Fig. 13. Sensitivity of IRR with RHI variance.

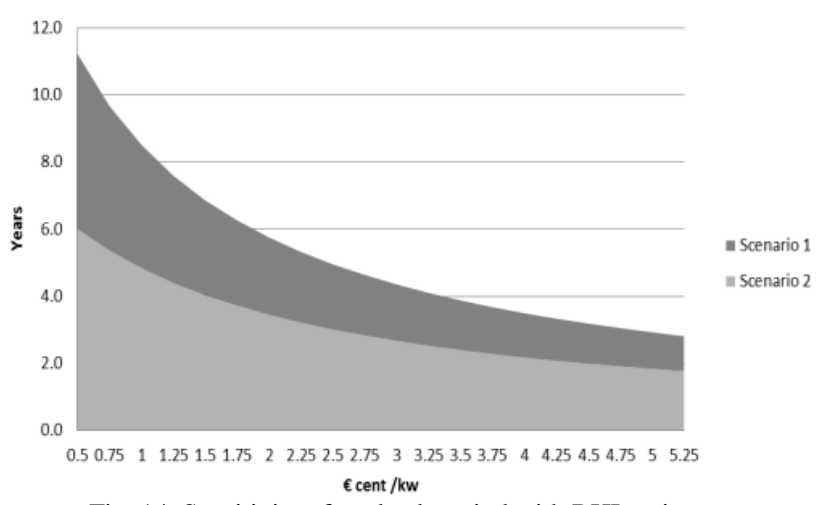

Fig. 14. Sensitivity of payback period with RHI variance.
If Coillte's recommendation of $1.5 \mathrm{c} / \mathrm{kwhr}$ is realized, the willow chip system, although having a lower NPV (see Fig. $12, € 475,409, € 420,957)$ signifying a lesser investment opportunity than scenario 2 , will offer an earlier return on investment (see Fig. 14, 2.8 years, 4 years) and a larger internal rate of return (see Fig. 13, 33.39\%, 21.58\%).

Whilst scenario 2 might still offer superior economic returns over the lifespan of the plant, the relative immaturity of the technology, larger capital outlay, specific feedstock requirement and smaller range of technologies available certainly show promising investment opportunities for lignocellulosic fuel conversion technologies.

\section{Feedstock Subsidies}

The maximum fuel prices that return a positive NPV under base case conditions are shown for each system. Scenario 2's (chicken litter combustion) feedstock is produced onsite at a fixed cost (-€12.60, disposal fee) with price sensitivity negligible. It is evident and of no surprise that willow chip feedstock price has a major impact on the NPV of scenario 2 (see Fig. 15). A reduction of circa $€ 15 / \mathrm{t} \mathrm{dm}$ in the cost of willow chip would give equal investment opportunities to both scenarios over the projected 15 year lifespan of the plant allowing for similar NPV's (see Fig. 15), PP's (see Fig. 16) and a positive IRR (see Fig. 17).

The results validate that modifications to the CAP (EFA Regulation) could potentially allow for increased income at production level, allowing producers to sell feedstock at a lower cost and thus incentivizing investment in LGB conversion technologies.

Results also indicate that a combination of reduced Value Added Tax (VAT) on Feedstock and increased taxation on fossil fuels could have a significant impact on achieving Ireland's energy goals.

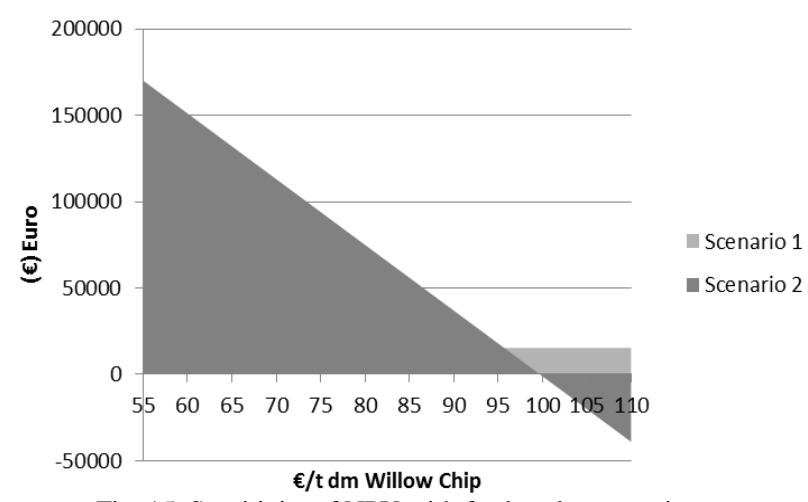

Fig. 15. Sensitivity of NPV with feedstock cost variance.

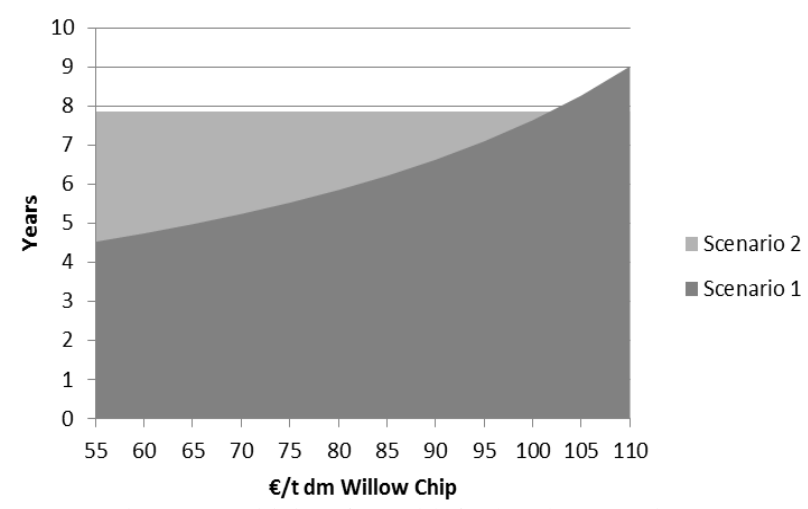

Fig. 16. Sensitivity of PP with feedstock cost variance. 


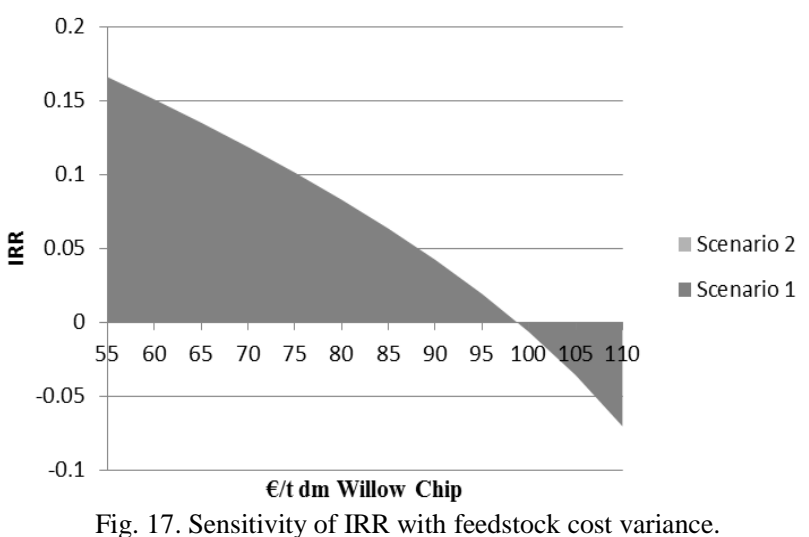

\section{CONCLUSION AND Discussion}

Ireland has a limited amount of economically viable LGB and conversion methods for energy production. At present, two major technologies are being targeted to convert LGB biomass into energy; thermo-chemical and bio-chemical.

Increased pressure on landfills to divert organic waste from landfill (1999/31/EC) combined with recent increases in landfill levies (Waste Management Landfill Levy) (Amendment) Regulations 2012 (SI No. 221 of 2012), (Waste Management Landfill Levy) (Amendment) Regulations 2013 (SI No. 194 of 2013) have promoted the use of alternative waste processing methods such as anaerobic digestion. Landfill levies are an aggressive fiscal measure that offers $\mathrm{AD}$ plants processing waste a supplementary income through gate fees. However, the levy also diminishes the financial attractiveness of investment in anaerobic digesters that utilize grass as feedstock, as they must pay a premium for feedstock produced. Established bioenergy markets like that in Sweden have identified, incentivized and committed to $\mathrm{AD}$ as a waste treatment and energy recovery method, through a range of regulatory and fiscal policy measures. In the long-term, anaerobic digestion facility treatment of biowaste may have the potential to cause a ripple effect, generating increased investment in the technology and use of alternative feedstocks such as LGB fuels, when the market equalizes. In the short term, digestion of grass feedstock is unlikely to make a significant impact in realizing Ireland's EU energy targets, as this conversion method is likely to be substantially dedicated to waste processing.

Notwithstanding this, lignocellulosic biomass fuels have the potential to make a significant contribution towards meeting Ireland's Res-H targets, provided favorable policy measures are put in place. This paper examines two potential applications of biomass energy utilization for broiler house heating. Access to fuels and alternative feedstocks within the agri-sector provide unique opportunities for early adoption in renewable biomass fuelled energy production.

The cases have been considered as two alternative investment scenarios for the same producer, who is currently considering replacing the conventional LPG space heating systems. The cases serve as an example of how minor adjustments to current policy measures, allied with the introduction of the RHI in 2016, could see rapid deployment of $\mathrm{RE}$ technologies and a vast reduction in impending $\mathrm{EU}$ fines.
The economic viability of biomass systems is dependent on a number of factors (capital cost, feedstock price, plant lifespan, discount factor etc.). The application of fiscal policies such as a capital grant or introduction of a RHI has potentially a major impact on investment of RE technologies. Combustion of poultry manure (onsite waste stream) does appear to be the superior investment opportunity in this case study. However, small scale $(<1 \mathrm{MW})$ poultry litter combustion is a relatively new technology with a reduced range of technologies available. Scenario 1, whilst economically unfavorable in this case study when compared to poultry litter combustion will have a market niche at different scales or for different industrial applications, provided fiscal incentives such as the proposed RHI in 2016 are introduced.

Regulatory policies can also be very effective in realizing bioenergy goals, as is seen by regulatory changes to onsite combustion of poultry manure (Commission Regulation (EU) No 592/2014) \& the diversion of organic waste from landfills (1999/31/EC), but are difficult to investigate quantitatively. Future qualitative data collection methods are proposed in order to fully investigate the effect of regulatory policy amendments.

Capital grants are required for targeted investment in processing, storage and marketing of LGB fuels in order to support RE infrastructure and correct supply chain issues.

The challenge for LGB fuels in Ireland is to be a competitive substitute, in terms of feedstock supply, conversion efficiency, sustainability and price, for oil, coal and gas whilst also meeting rapidly approaching EU targets. A combination of policies is required over the short, medium and long term to provide a sustainable $\&$ affordable climate for RE deployment.

The short term focus is to meet Ireland's EU 2020 targets. Aggressive Government led fiscal policy instruments similar to the UK RHI provide project feasibility, market confidence and a route to market for established energy crop plantations.

The medium \& long term policy goals must focus on the post 2020 period and economically sustainable policy measures. In the climate and energy policy framework for 2030, the European Commission proposes that the EU set itself a target of $27 \%$ total energy consumption from RE. A similar approach to Sweden where the application of a policy mix of regulatory \& fiscal policies (ban on landfilling organics \& combustible waste, explicit preference given to biogas vehicles when tendering for municipal and regional fleets and services, 5 years of road tax exemption for biogas vehicles etc.) is required to incentivize public and private operations to invest in sustainable RE technologies.

\section{REFERENCES}

[1] F. Polzin, M. Migendt, F. A. Täube, and P. V. Flotow, "Public policy influence on renewable energy investments - A panel data study across OECD countries," Energy Policy, vol. 80, pp. 98-111, 2015.

[2] P. Quirion, "Complying with the Kyoto protocol under uncertainty: Taxes or tradable permits?" Energy Policy, vol. 38, pp. 5166-5173, 2010.

[3] F. R. Aune, H. M. Dalen, and C. Hagem, "Implementing the EU renewable target through green certificate markets," Energy Economics, vol. 34, no. 4, pp. 992-1000, 2012.

[4] J. A. Mathews, S. Kidney, K. Mallon, and M. Hughes, "Mobilizing private finance to drive an energy industrial revolution," Energy Policy, vol. 38, pp. 3263-3265, 2010. 
[5] Taxes and Incentives for Renewable Energy, KPMG International, 2012.

[6] Draft Bioenergy Plan, Department for Communications E. \& N. R, 2014.

[7] The Economic Benefits from the Development of Bioenergy in Ireland to Meet 2020 Targets, SEAI, 2012.

[8] A. Mbzibain, T. J. Hocking, G. Tate, and S. Ali, "Renewable enterprises on UK farms: Assessing levels of uptake, motivations and constraints to widespread adoption," Biomass and Bioenergy, vol. 49, pp. 28-37, 2013.

[9] P. Komor and M. Bazilian, "Renewable energy policy goals, programs, and technologies," Energy Policy, pp. 1873-1881, 2005.

[10] J.-B. Spitzley, C. Najdawi, J. Geiss, T. Schmedding, E. Giovannetti, and E. Smith, "Keeping track of renewable energy targets towards 2020: EU tracking roadmap 2014," Intelligent Energy Europe Programme, 2014.

[11] C. Gallagher and J. D. Murphy, "What is the realistic potential for biomethane produced through gasification of indigenous willow or imported wood chip to meet renewable energy heat targets?" Applied Energy, vol. 108, pp. 158-167, 2013.

[12] The Support of Electricity from Renewable Energy Sources, the European Commission, 2005.

[13] J. Scheer, S. Stanley, and M. Clancy, "Ireland's sustainable energy supply chain opportunity," SEAI, 2014.

[14] Development of Ireland's First Biomass CHP Plant, SEAI, 2006.

[15] M. Clancy and F. Gaffney, "Quantifying Ireland's fuel and $\mathrm{CO}_{2}$ emissions savings from renewable electricity in 2012," Wilton Park House, Wilton Place, Dublin 2, Ireland, 2014.

[16] COFORD, Irish Forests and Renewable Energy, 2014.

[17] M. Foley, “An RHI for Ireland - An informed perspective," presented at IrBea Conference, Dublin, 2014

[18] M. Howley, M. Holland, K. O'Rourke, L. P. Ó. Cleirigh, S. Malone, and B. Ó. C. Consulting, Renewable Energy in Ireland 2012, Unit EPSS, 2014.

[19] M. Clancy, Renewable Heat in Ireland to 2020, Dublin, Ireland: Energy Modelling Group S., 2015.

[20] Tillage Sector Development Plan, Teagasc Tillage Crop Stakeholder Consultative Group, 2012.

[21] Teagasc. (March 2014). Tillage sectoral energy crop development group. [Online]. Available: http://www.teagasc.ie/publications/2014/3130/Tillage_Sectoral_Ener gy_Crop_Development_GroupPlan2014.pdf

[22] Overview of CAP Reform 2014-2020, Agricultural Policy Perspectives Brief, 2013.

[23] Renewables 2012 Global Status Report, Paris: REN 21, 2012.

[24] F. Aaskov, "The impact of the renewable heating support scheme in UK," Aebiom, 2014.

[25] J. B. OFGEM, "Non-domestic renewable heat incentive," presented at IrBea Conference, Dublin, 2015.

[26] P. M. Connor, L. Xie, R. Lowes, J. Britton, and T. Richardson, "The development of renewable heating policy in the United Kingdom," Renewable Energy, vol. 75, pp. 733-744, 2015.

[27] Bioenergy in Sweden 2010-2020 - A Review of Amounts, Future Trends and Research, Göteborg: Swedish Environmental Research Institute, 2011.

[28] B. Driver, "Efficient bioenergy stratagies in the national renewable energy action plans," 2010.

[29] K. Ericsson, S. Huttunen, L. J. Nilsson, and P. Svenningsson, "Bioenergy policy and market development in Finland and Sweden," Energy Policy, vol. 32, pp. 1707-1721, 2004.

[30] M. T. Loibnegger, "Telling the story in Austria - Sustainable wood energy supply,” Graz: Intelligent Energy Europ — IEE, 2010.
[31] E. Vagonyte, "Use of bio-heat from solid biomass in Europe," Intelligent Energy Europe, Aebiom, 2009.

[32] Non-Domestic Renewable Heat Incentive, Ofgem, 2014.

[33] J. Finnan and S. D. Hemp, "A more sustainable annual energy crop for climate and energy policy," Energy Policy, vol. 58, pp. 152-162, 2013.

[34] A. O'Mahoney, F. Thorne, and E. Denny, "A cost-benefit analysis of generating electricity from biomass," Energy Policy, vol. 57, pp. 347-354, 2013.

[35] D. Styles, F. Thorne, and M. B. Jones, "Energy crops in Ireland: An economic comparison of willow and Miscanthus production with conventional farming systems," Biomass and Bioenergy, vol. 32, pp. 407-421, 2008.

[36] C. Barbier and S. Econnect, "Sustainable energy for the rural village environment," Tipperary: Concerto, 2010.

[37] Energy Use in Agriculture, SEAI, 2011.

[38] Wood Burning Technologies for Irish Consumers - Best Practice Guide, Wilton Park House, Wilton Place, Dublin Sustainable Energy Authority of Ireland.

[39] Renewable Energy Technologies: Cost Analysis Series, Bonn, Germany: IRENA, 2012.

[40] T. Bruckner, H. Chum, A. Jäger-Waldau, A. Killingtveit, L. Gutiérrez-Negrín, J. Nyboer, et al., "IPCC special report on renewable energy sources and climate change mitigation," Cambridge, United Kingdom and New York, NY, USA, 2011.

[41] (BOI) B. o. I. Green Business Loan Green Business Loan. (2011). [Online]. Available: http://businessbanking.bankofireland.com/fs/doc/wysiwyg/SM143-37 $-1064 \% 20 \mathrm{R}(02-11) \% 20 \mathrm{r} \% 20 \mathrm{nc} . \mathrm{pdf}$

[42] J. Chau, T. Sowlati, S. Sokhansanj, F. Preto, S. Melin, and X. Bi, "Techno-economic analysis of wood biomass boilers for the greenhouse industry," Applied Energy, vol. 86, no. 3, pp. 364-371, 2009.

[43] D. G. Wright, P. K. Dey, and J. Brammer, "A barrier and techno-economic analysis of small-scale bCHP (biomass combined heat and power) schemes in the UK," Energy, pp. 1-14, 2014.

[44] A. Nolan, K. M. Donnell, G. J. Devlin, J. P. Carroll, and J. Finnan, "Economic analysis of manufacturing costs of pellet production in the Republic of Ireland using non-woody biomass," The Open Renewable Energy Journal, vol. 3, pp. 1-11, 2010.

[45] D. Y. Huang and P. N. Hewitt, "Comparative techno-economic analysis of biomass fuelled combined heat and power for commercial buildings," in Proc. ICAE 2012, Suzhou, China, 2012.

[46] C. Patel, P. Lettieri, S. J. R. Simons, and A. Germanà, "Techno-economic performance analysis of energy production from biomass at different scales in the UK context," Chemical Engineering Journal, vol. 171, pp. 986-996, 2011.

[47] CAP 2015 an Introduction to Direct Payment, Dublin: Department of Agriculture, Food and the Marine, 2014.

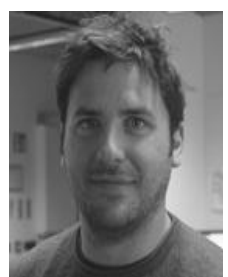

Martin W. Leahy is currently a postgraduate student with the Institute of Technology Carlow, Ireland, undertaking a masters by research. He already holds an honours degree in mechanical engineering. Coming from an agricultural background, Martin worked as a design engineer for a prominent dairy systems manufacturer before deciding to return to college to pursue postgraduate studies. Martin's research interests include biomass systems, economics and policy design. His current research project is entitled "Comparative study of the relative economics of energy production from lignocellulosic and grass biomass fuel in Ireland". 